Supporting Information

\title{
Co-Delivery of Cisplatin Prodrug and Chlorin e6 by Mesoporous Silica Nanoparticles for Chemo-Photodynamic Combination Therapy to Combat Drug Resistance
}

Wei Zhang ${ }^{\mathrm{a}, \mathrm{b}}$, Jianliang Shen ${ }^{\mathrm{c}}$, Hua Su${ }^{\mathrm{a}}, \mathrm{Ge} \mathrm{Mu}^{\mathrm{a}}$, Jing-Hua Sun ${ }^{\mathrm{a}}$, Cai-Ping Tan ${ }^{\mathrm{a}}$, Xing-Jie Liang ${ }^{\mathrm{b}} *$, Liang-Nian $\mathrm{Ji}^{\mathrm{a}}$, Zong-Wan $\mathrm{Mao}^{\mathrm{a} *}$

${ }^{a}$ MOE Key Laboratory of Bioinorganic and Synthetic Chemistry, School of Chemistry and Chemical Engineering, Sun Yat-sen University, Guangzhou 510275, P. R. China

${ }^{b}$ CAS Center for Excellence in Nanoscience, CAS Key Laboratory for Biological Effects of Nanomaterials \& Nanosafety, National Center for Nanoscience and Technology, Beijing 100190, P. R. China

${ }^{c}$ Department of Nanomedicine, Houston Methodist Research Institute, Houston, Texas 77030, United States

Corresponding Author

*Authors to whom correspondence should be addressed.

*E-mail: cesmzw@ mail.sysu.edu.cn, liangxj@nanoctr.cn. 


\section{Table of Contents}

Scheme S1 Synthesis routes of Ad-PEG, CD-PEI and cisplatin prodrug...........S3

Figure $\mathbf{S 1}{ }^{1} \mathrm{H}$ NMR spectrum of CD-PEI....................................S4

Figure S2 ${ }^{1} \mathrm{H}$ NMR spectrum of Ad-PEG..................................... 4

Figure S3 ESI-MS spectrum of $c, c, t-\left[\mathrm{Pt}\left(\mathrm{NH}_{3}\right)_{2} \mathrm{Cl}_{2}(\mathrm{OH})\left(\mathrm{O}_{2} \mathrm{CCH}_{2} \mathrm{CH}_{2} \mathrm{CO}_{2} \mathrm{H}\right)\right] \ldots \ldots . \mathrm{S} 5$

Figure S4 FT-IR spectra of MSNs-OH before CTAB extraction, MNSs-OH after

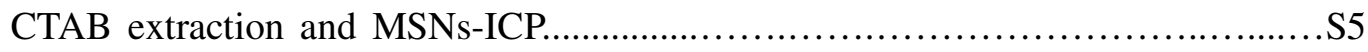

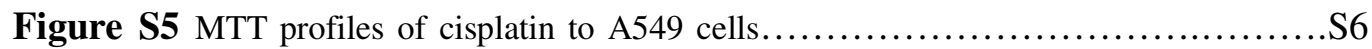

Figure S6 Singlet oxygen detection by photooxidation of RNO under light irradiation.........S6 

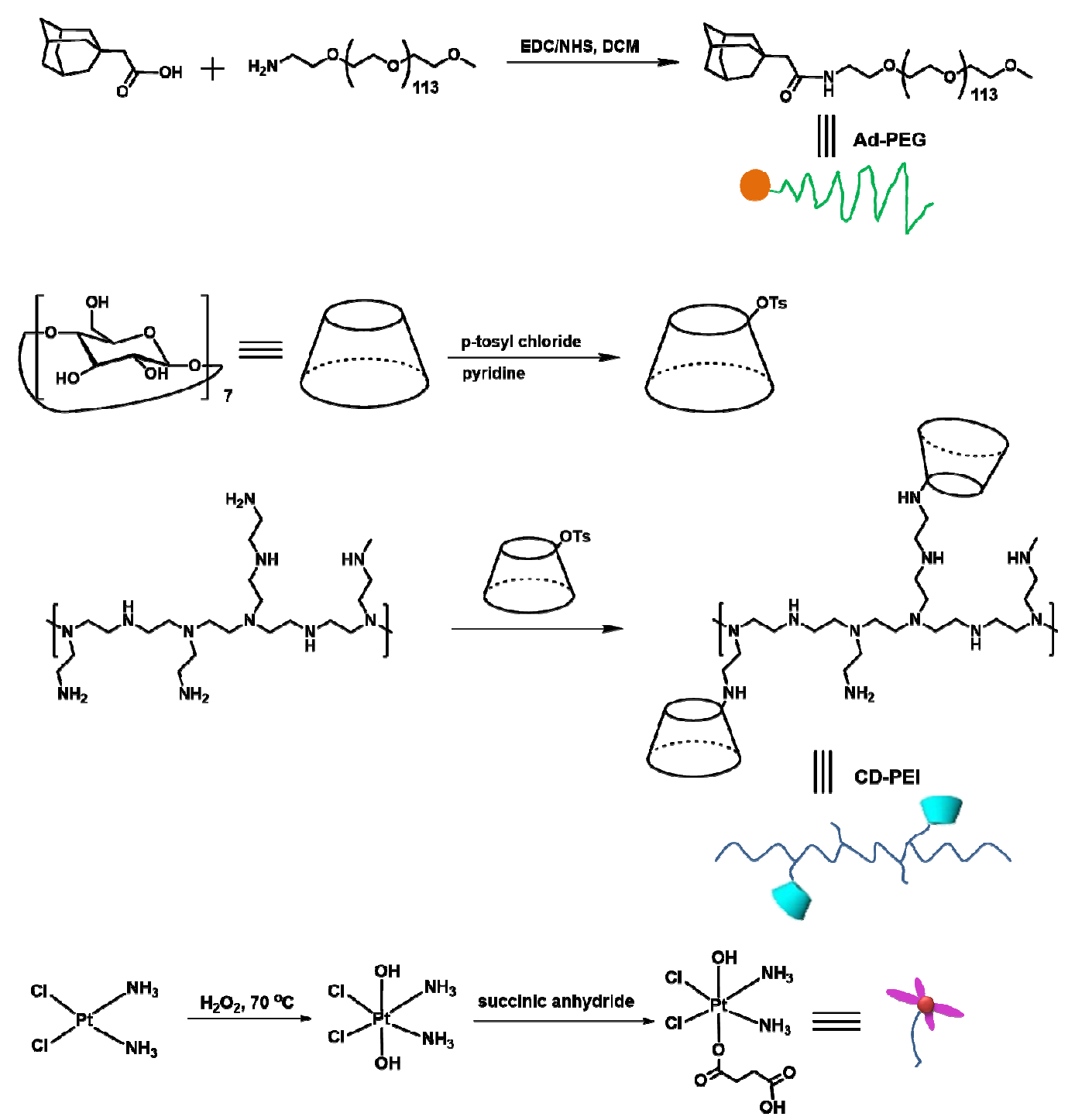

Scheme S1. Synthesis routes of Ad-PEG, CD-PEI and cisplatin prodrug. 


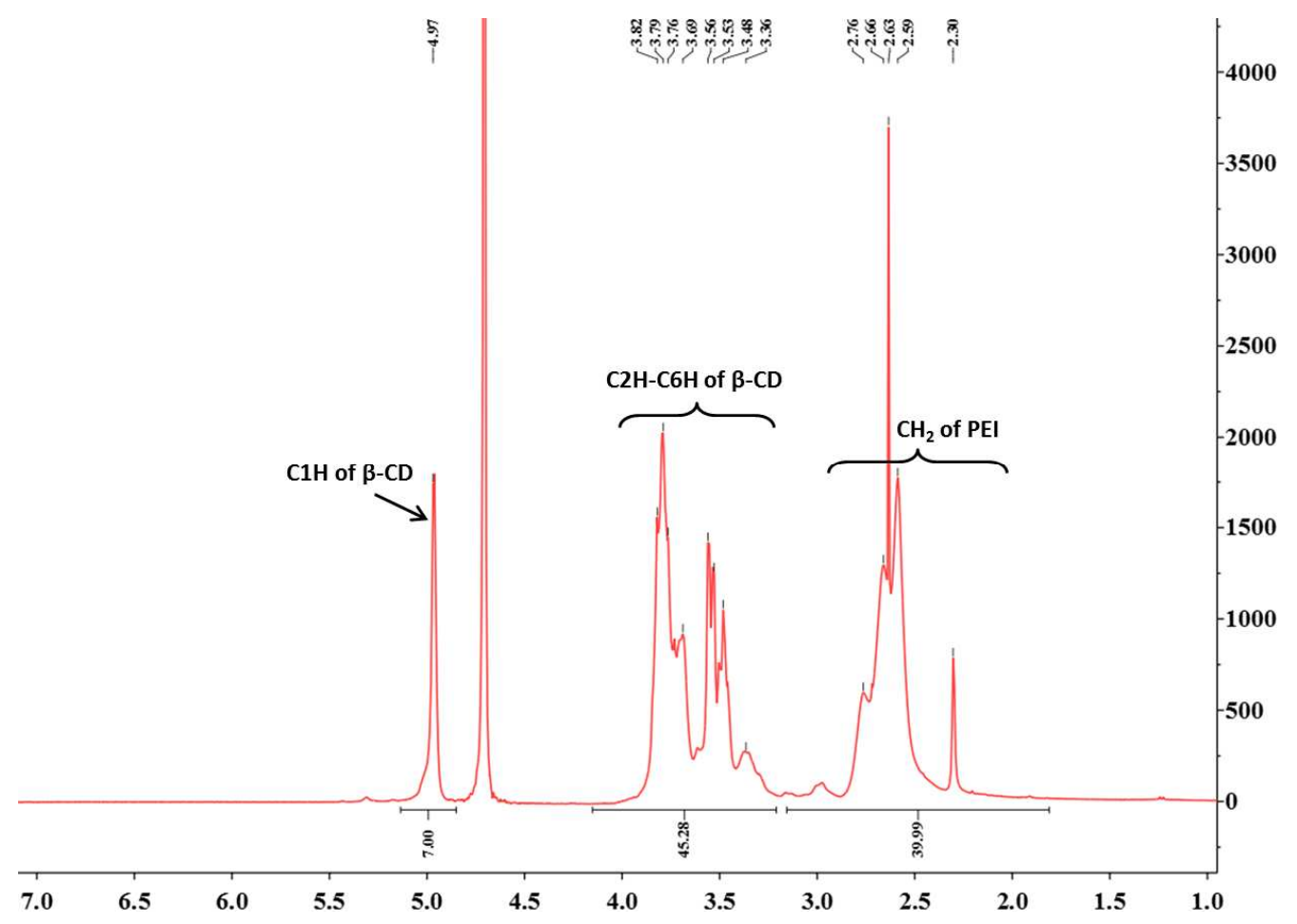

Figure $\mathrm{S} 1 .{ }^{1} \mathrm{H}$ NMR spectrum of CD-PEI.

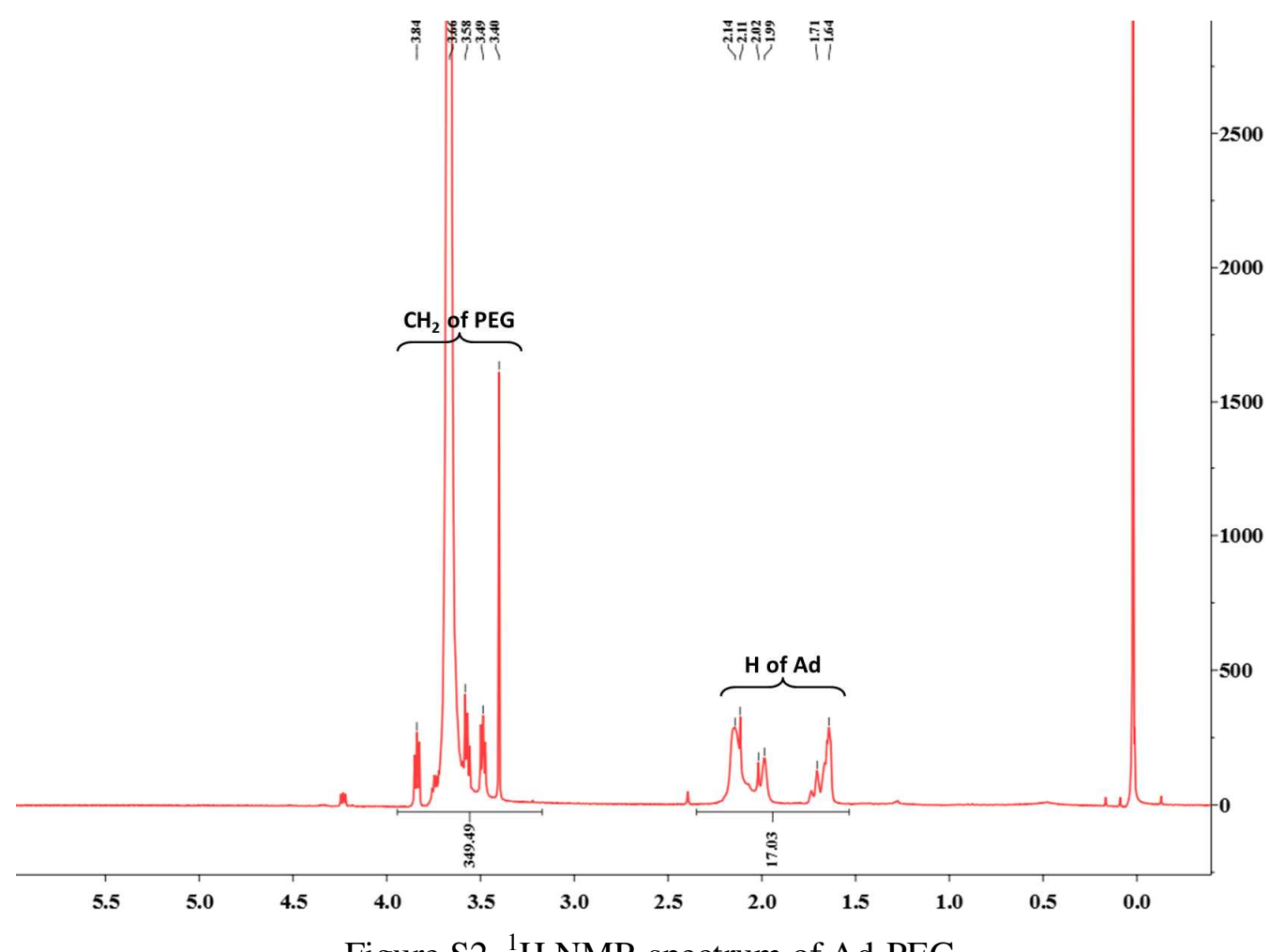

Figure S2. ${ }^{1} \mathrm{H}$ NMR spectrum of Ad-PEG. 


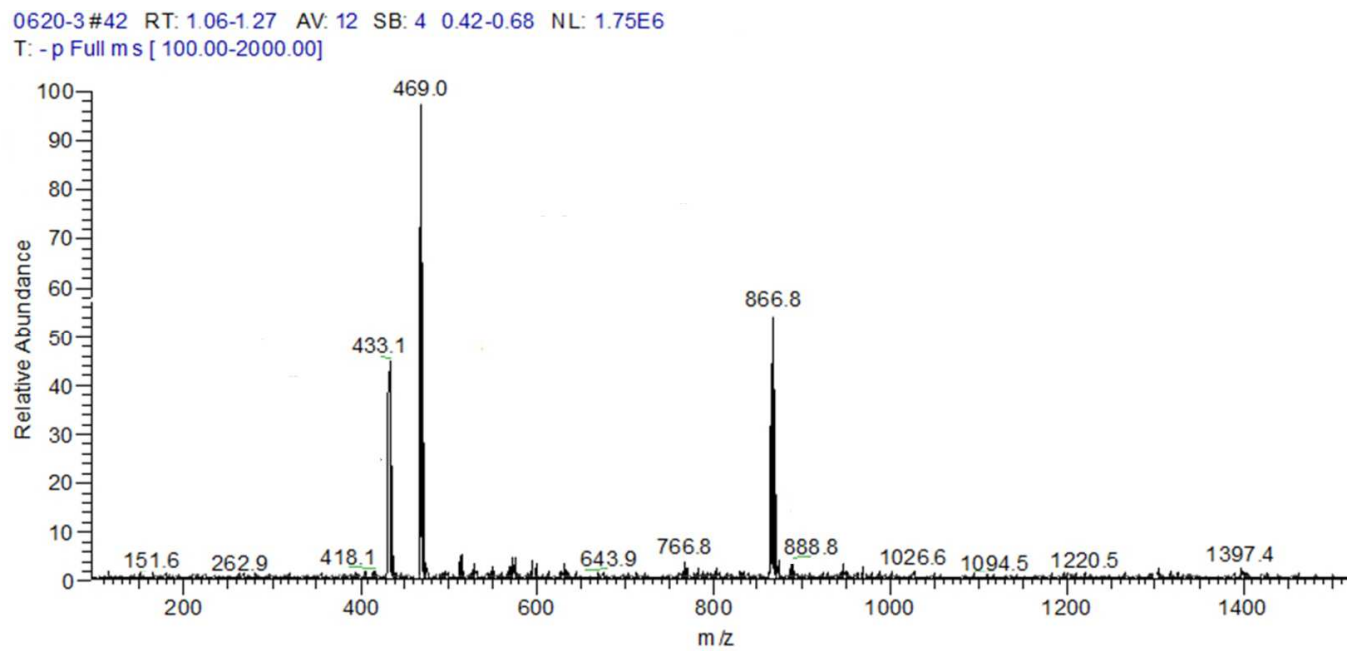

Figure S3. ESI-MS spectrum of $c, c, t-\left[\mathrm{Pt}\left(\mathrm{NH}_{3}\right)_{2} \mathrm{Cl}_{2}(\mathrm{OH})\left(\mathrm{O}_{2} \mathrm{CCH}_{2} \mathrm{CH}_{2} \mathrm{CO}_{2} \mathrm{H}\right)\right]$.

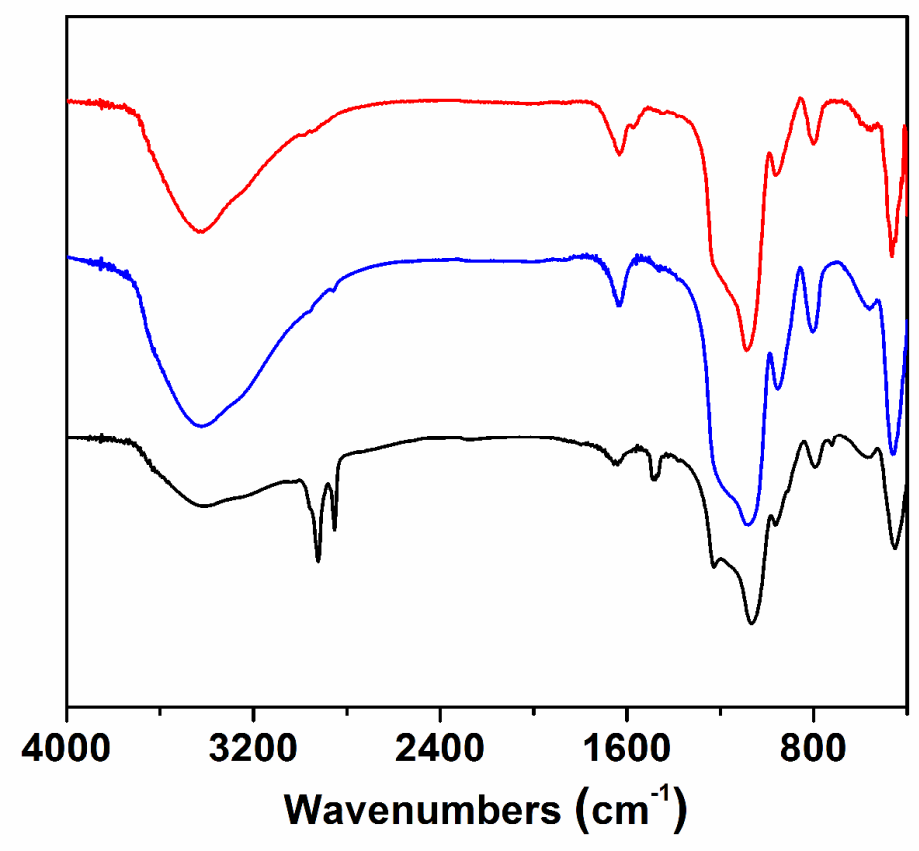

Figure S4. FT-IR spectra of MSNs-OH before CTAB extraction (black), MNSs-OH after CTAB extraction (blue) and MSNs-ICP (red). 


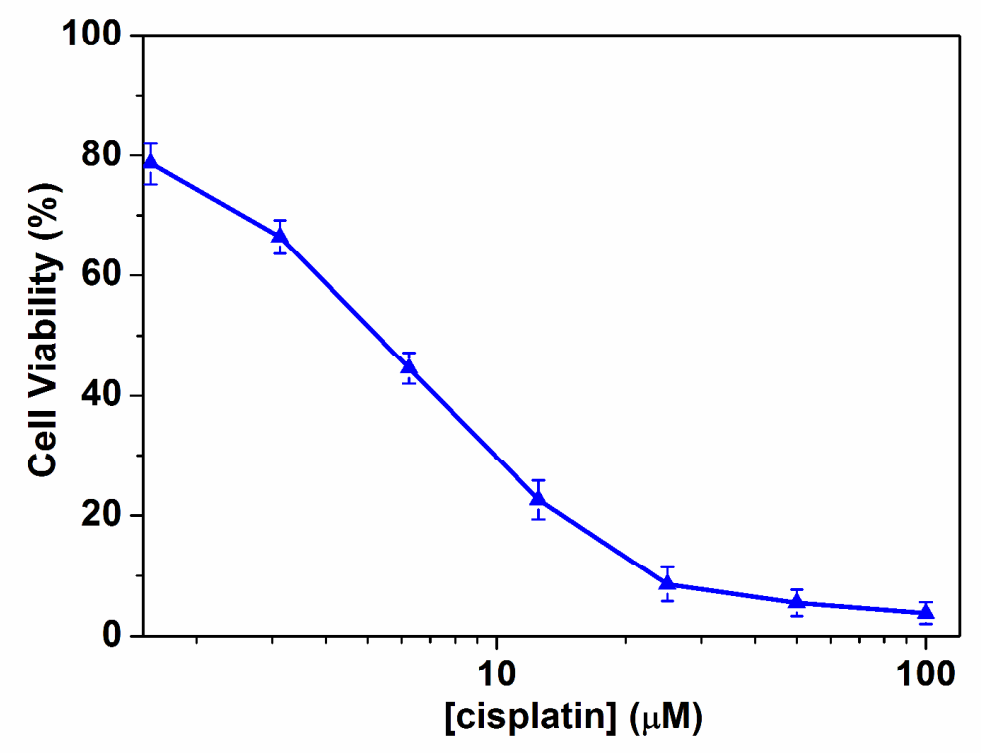

Figure S5. MTT profiles of cisplatin to A549 cells.

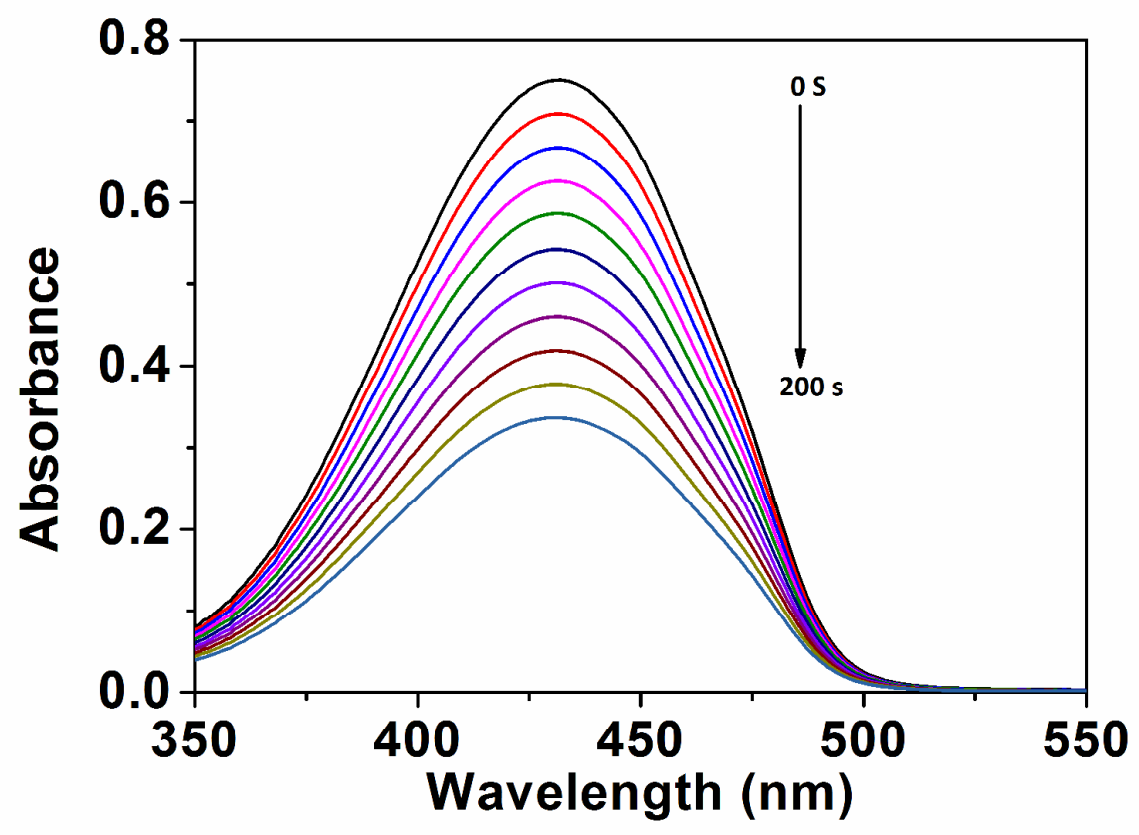

Figure S6. Singlet oxygen detection by photooxidation of RNO under light irradiation. To the solution of p-nitrosodimethylaniline $(\mathrm{RNO}, 30 \mu \mathrm{M})$, imidazole $(0.5 \mathrm{mM})$ in PBS (10 mM, pH=7.4) was added MSNs/Ce6/Pt (50 $\mu \mathrm{g} / \mathrm{mL})$, then the solution was irradiated with $660 \mathrm{~nm}$ light at the power density of $10 \mathrm{~mW} / \mathrm{cm}^{2}$ for different periods of time. 